\title{
Do the Industries have Improvement Focus?-A Survey In Coimbatore District
}

\author{
Dr. J. Sekkizhar ${ }^{1}$ \\ \{sekkizhar@psgim.ac.in $\left.{ }^{1}\right\}$ \\ Associate Professor, PSG Institute of management, PSG College of Technology, Coimbatore, INDIA ${ }^{1}$
}

\begin{abstract}
The A good and scientific management should be goal oriented. However, in India scenario especially in small cities such as Coimbatore, this is big question. In order to identify the facts on it, 50 companies are selected and enquired about their focus. The results were obviously sad.
\end{abstract}

Keywords: Focus, Toc, Goal, Business, Coimbatore.

\section{Introduction}

A good and scientific management should be goal oriented. Good leaderships should be transformational rather than transactional. A good system should be principal oriented rather than the person oriented. The study is whether the industries have improvement focus or not which is present in and around Coimbatore district. The scope includes the conducting survey among the professionals working in industries which is located in and around Coimbatore district about the prevalence of improvement focus in their industry. The objective of the study is to study the improvement focus level of the industries toward the company goal.

\section{Framework}

Goldratt (1984) introduced the Drum buffer rope concept but the actual Theory of constraint means "FOCUS". Business process efficiency can be improved by Focus and Efficiency is increased under limited resources which are called constraints. TOC scheduling programming was the chief requirement based arrangement ahead of time and planning framework to help fabricating firms to have a conclusive serious edge by assisting with accomplishing their goal of cash now and later on. (Singh and Misra, 2018). TOC has methods which are used for controlling the bottleneck that prevents the system from achieving its goal.

Local improvements are not global improvements (Goldratt, 1984) and Local optimization is due to the global whole as in TOC (Freedman, J., 1997). TOC finds a "gain orientation" on considering three components: mental model, measure and methodology (Pacheco et al., 2019). TOC is not only involved in the Production Sector but also in many sectors. To measure the performance of the system related to its goal, financial and operational measures are used. Increase in profit is due to decrease in inventory (Mabin\&Balderstone, 2003). Local improvement needs global understanding for focusing on it. Both local improvement and global focus are needed for the organization's achievement (Kalina- 
Kaminsky, 2005). TOC has an approach for the system improvement by focusing on throughput but not on the cost (Moss and Kay, 2002).

\section{Research methodology}

Here we need a structured data which is collected using the online questionnaire. It is collected from the professionals who are working in the industries which are located in and around Coimbatore district. A Survey using the Questionnaire will be taken with usage of 30 -50 samples for the analysis. The survey will be taken in the companies which are situated in and around Coimbatore. This survey describes the various types of sectors. Majority six percentage represents the IT sector. The various nature of business are Accounting. BPO, Data Enhancement, KPO industry, Manufacturing and Banking sectors and these constitutes the minority of the people. PSPP software is used for the analysis.

\section{Analysis and interpretation}

\subsection{What the goal the Coimbatore companies do have?}

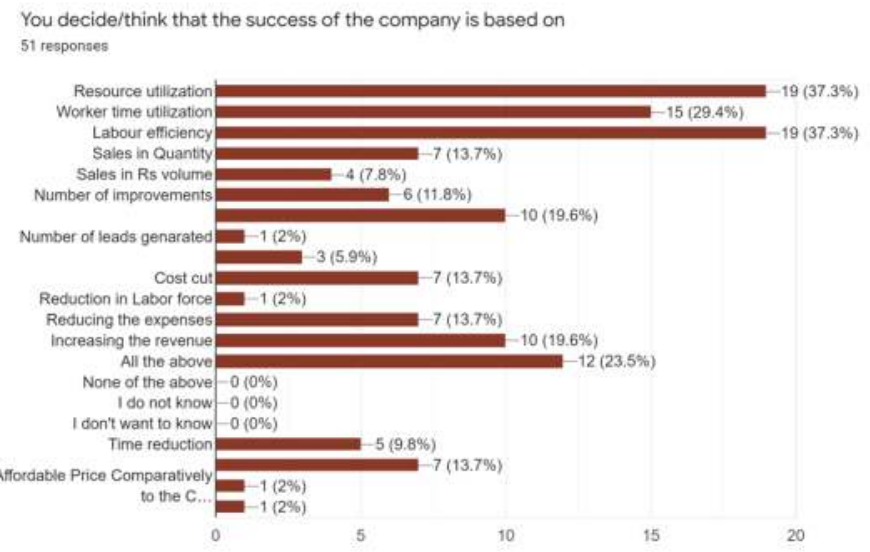

This graph depicts the reason for success of the company. The factors are Resource utilization and labor efficiency in which both contributes to about thirty seven percentage. Thirty percentages is contributed by work time utilization. Here the utilization of man, money and material in correct proportion is a basis for success of the company

The study reveals that most of the companies absolutely no focus (or minimal) on goal of money making through sales improvement. No importance given to number of lead generation, number of product sold and even sales volume. These are all considered local problems of marketing department and not given sufficient attention by the top management. Contrarily, the most (37\%) of the top managements always focus on Resource or labor utilization and cost efficiency of the worker or work centers. As TOC said, common sense is uncommon every where. Full utilization of the resources creates only work in process 
inventory only but not throughput in terms of sales (Goldratt, 1985). Next focus of top managements is always on cost reduction and only some portion $(19 \%)$ are really interested revenue generation.

\subsection{Where the goal of the companies is discussed?}
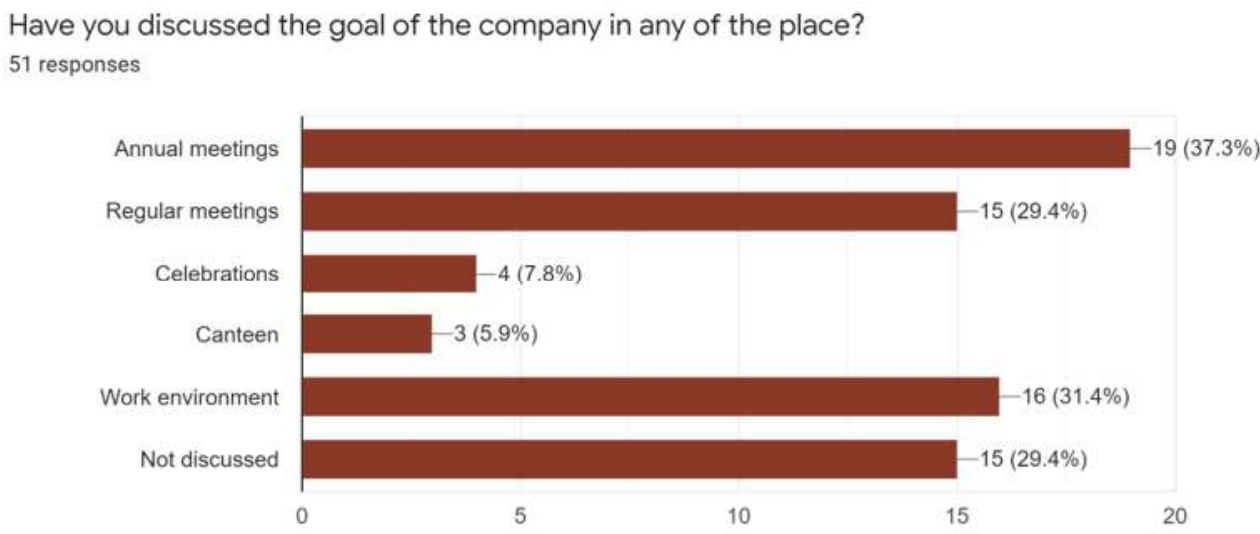

This graph represents the places where the goal is discussed. Those are Annual Meetings, Regular meetings, Celebrations, Canteen and work environment and not discussed. The goal and objective of the company should reach to all levels of employee present in the organization which ensures a smooth road map in achieving the goal and focus on their improvement process. 29.4\% Coimbatore based companies are not yet started their discussions on their business goal.

\subsection{ERP sleeps or be active?}

How much advanced planning software (like ERP) systems do you have?

50 responses

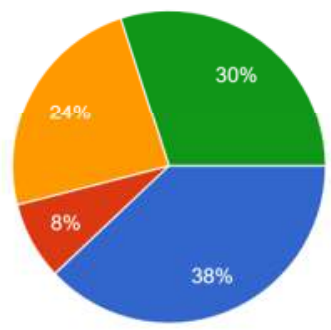

No ERP. We use excel alone

Very low end management systems we have

Useful and moderate level systems

- Advanced systems we have 
How much percentage of current software system utilized?

49 responses
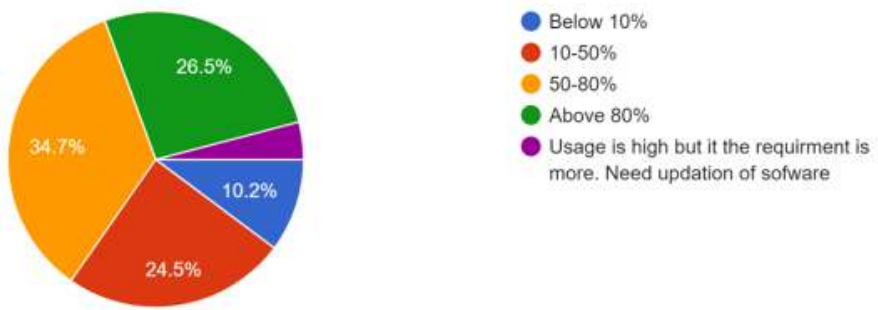

more. Need updation of sofware

Thirty eight percentage represents that they are is no ERP and use Excel alone. Thirty percentage of companies have advanced systems. Twenty four percentages responded it as useful and moderate level systems. Few people voted that they have very low end management systems. Availability and usage of advanced planning software denotes the focus on improvements in the planning.

However, Majority depicts that there is $50-80 \%$ usage. Minority depicts that usage is high and it needs update. Twenty four percentages used $10-50 \%$ of the current software system. Only Twenty six percent of the companies utilizes above $80 \%$ of the current software. Around ten percentage of the companies use only around $10 \%$ of the current software system. By knowing about the utilization of current software system it tells about the usage and benefits and pit falls about the software which will pave the way for improvement focus.

4.4. What type of improvement initiatives do the industries implement?

What type of Improvement process are you using?

50 responses

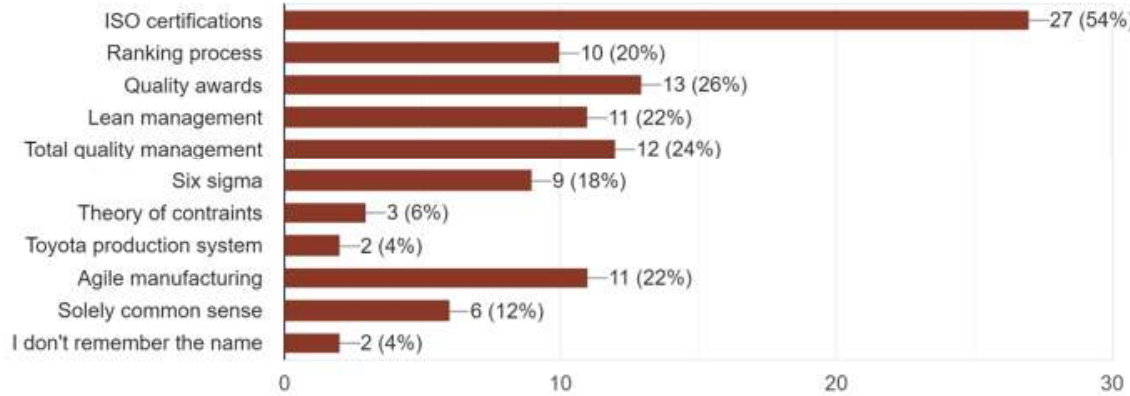

Fifty percentages of people uses ISO certification. Twenty six percent is used by quality awards. Twenty two percentages uses lean management. Twenty four percent Forty two percent of company does it, to satisfy the customer needs. But the company must know the needs. Still twelve percent of company doesn't know why do they use the technique; how benefit it is; and how it helps the company. 
[1] Freedman, J. (1997). FAR's TOC study reinforces the need for constraints accounting. Strategic Finance, 78(10), 66.

[2] Goldratt, E. M., \& Cox, J. (1984). The goal: excellence in manufacturing. North River Press.

[3] Kalina-Kaminsky, C. (2005). A statistical analysis of the theory of constraints. The University of Texas at Arlington.

[4] Mabin, V. J., \&Balderstone, S. J. (2003). The performance of the theory of constraints methodology: analysis and discussion of successful TOC applications. International Journal of Operations \& Production Management.

[5] Moss, H. K. (2002). The application of the theory of constraints in service firms. Clemson University.

[6] Singh, K., \&Misra, S. (2018). Theory of Constraints for Managing Downstream Supply Chain in Indian FMCG Sector: A Literature Review. Journal of Supply Chain Management Systems, 7(1).

[7] D. S. Vijayan, A. Mohan, J. J. Daniel, V. Gokulnath, B. Saravanan, and P. D. Kumar, "Experimental Investigation on the Ecofriendly External Wrapping of Glass Fiber Reinforced Polymer in Concrete Columns," vol. 2021, 2021. 